\title{
Implementing a Systematic Voiding Program for Patients With Urinary Incontinence After Stroke
}

\author{
Beverley French', Lois H. Thomas', Joanna Harrison', Christopher R. Burton', \\ Denise Forshaw', Joanne Booth ${ }^{3}$, David Britt ${ }^{4}$, Francine M. Cheater, \\ Brenda Roe ${ }^{6}$, and Caroline L. Watkins'; on behalf of the ICONS project team \\ and the ICONS Patient, Public and Carer Involvement Groups
}

\begin{abstract}
We explored health professionals' views of implementing a systematic voiding program (SVP) in a multi-site qualitative process evaluation in stroke services recruited to the intervention arms of a cluster randomized controlled feasibility trial during 201 I-2013. We conducted semi-structured group or individual interviews with 38 purposively selected nursing, managerial, and care staff involved in delivering the SVP. Content analysis of transcripts used normalization process theory (NPT) as a pre-specified organization-level exploratory framework. Barriers to implementing the SVP included perceived lack of suitability for some patient groups, patient fear of extending hospital stay, and difficulties with SVP enactment, scheduling, timing, recording, and monitoring. Enablers included the guidance provided by the SVP, patient and relative involvement, extra staff, improved nursing skill and confidence, and experience of success. Three potential mechanisms of consistency, visibility, and individualization linked the SVP process with improvements in outcome, and should be emphasized in SVP implementation.
\end{abstract}

\section{Keywords}

interviews; knowledge transfer; nursing; program evaluation; qualitative analysis; research, clinical; stroke; urinary incontinence; qualitative; normalization process theory; UK

\section{Introduction}

Stroke is the third largest cause of death and the largest single cause of severe adult disability (Bonita, 1992), with up to 95,000 people per annum surviving after stroke in the United Kingdom. Although stroke is primarily a disease of later life, half of all strokes occur in people less than 70 years old (Bamford et al., 1988). Urinary incontinence (UI) following stroke is common, with prevalence estimates suggesting around half of stroke survivors are affected in the acute phase and findings similar across countries (Kolominsky-Rabas, Hilz, Neundoerfer, \& Heuschmann, 2003; Lawrence et al., 2001; Nakayama, Jorgensen, Pedersen, Raaschou, \& Olsen, 1997). As many as $43.5 \%$ and $38 \%$ of stroke survivors remain incontinent at 3 months and 1 year, respectively (Williams, Srikanth, Bird, \& Thrift, 2012). In longer term stroke survivors (on average 9 years post-stroke), prevalence has been reported as 17\% (Jorgensen, Engstad, \& Jacobsen, 2005).

The symptoms of UI are reported to be more severe and have more of an effect on the lives of stroke survivors, when compared with other groups of people (Brittain et al., 2000). Incontinence is not just a physical problem, but affects what people can do, for example, participate in rehabilitation activities, and how they feel. Depression is twice as common in stroke survivors who are incontinent (Brittain, 1998) and there may be a link between depression associated with urinary symptoms and suicide (Brittain \& Castleden, 1998). Continuing incontinence is associated with poor outcome in both stroke survivor and carer (Nakayama et al., 1997). Furthermore, the negative

\footnotetext{
'University of Central Lancashire, Preston, United Kingdom

${ }^{2}$ Bangor University, Bangor, United Kingdom

${ }^{3}$ Glasgow Caledonian University, Glasgow, United Kingdom

${ }^{4}$ University of Liverpool, Liverpool, United Kingdom

${ }^{5}$ University of East Anglia, Norwich, United Kingdom

${ }^{6}$ Edge Hill University, Ormskirk, United Kingdom

Corresponding Author:

Lois H. Thomas, School of Health Sciences, University of Central

Lancashire, Preston, PRI 2HE, England, UK.

Email: Ihthomas@uclan.ac.uk
} 
social consequences of dealing with incontinence for both survivor and carer cannot be ignored, as both may become isolated and marginalized (Brittain \& Shaw, 2007). If post-stroke incontinence is targeted early, not only is there the potential to reduce the poor outcome of stroke associated with incontinence but also the negative social consequences associated with it post-hospital discharge.

Problems with continence have been shown to be amenable to early intervention, particularly in the 3 months following stroke (Marinkovic \& Badlani, 2001). Stroke outcome may be better in those stroke survivors who remain continent or regain continence (Barer, 1989). Although there are problems with attributing better stroke outcome to improvements in continence, it is possible early intervention aimed at promoting recovery from incontinence may improve morale and self-esteem and therefore speed overall stroke recovery (Barer, 1989; Patel, Coshall, Rudd, \& Wolfe, 2001). It is also possible that the recovery of continence reduces barriers to participation in rehabilitation activity.

Current clinical guidelines for the management of UI (Canadian Stroke Network, 2010; Intercollegiate Stroke Working Party, 2012; Miller et al., 2010; National Collaborating Centre for Women's and Children's Health, 2013; National Stroke Foundation, 2010) recommend behavioral strategies targeted to the type of incontinence (e.g., bladder training) as first-line therapy for both men and women. However, despite the availability of clinical guidelines, U.K. national audit data suggest incontinence is often poorly managed (Intercollegiate Stroke Working Party, 2012; Jordan et al., 2011). In the latest Sentinel Stroke National Audit Programme (Royal College of Physicians, 2014), 17\% of incontinent patients did not have a plan for continence management within 3 weeks of arrival, a statistic described by the authors as "terrible."

In the hospital setting, nurses are the main providers of continence care (Dumoulin, Korner-Bitensky, \& Tannenbaum, 2007). Nurses find managing continence in the context of stroke challenging (Booth, Kumlien, Zang, Gustafsson, \& Tolson, 2009), with over-reliance on urinary catheterization (a drainage tube placed in the bladder) as a management strategy especially in the acute phase of illness (Cowey, Smith, Booth, \& Weir, 2012). These difficulties are not limited to stroke services, with persistent reports of poor assessment and management practices in generic services (Wagg, Lowe, Peel, \& Potter, 2008). Nurses report difficulty in assessing, diagnosing, treating, and managing UI (Cooper \& Watt, 2003; Keilman \& Dunn, 2010). If not treated, incontinence will remain a distressing problem for a significant minority of patients in the longer term (Pilcher \& MacArthur, 2012).
While there is a lack of education about continence in nursing (McClurg et al., 2013), improving education alone is unlikely to be sufficient to change practice (Forsetlund et al., 2009). Changes to clinical practice are influenced by how people evaluate the health care innovation and its supporting evidence, and the social and organizational context for implementation (Flottorp et al., 2013). These interactions will determine if new ways of working are successfully embedded and become routine. There is a research review of factors influencing UI management in long-term care settings (Roe et al., 2011), but we found only one process evaluation of implementing new practices for UI in long-term care (Ouslander, Griffiths, McConnell, Riolo, \& Schnelle, 2005), and none related to acute care or rehabilitation settings.

We introduced a systematic voiding program (SVP) designed to help people regain continence in the early phases after stroke in a recent cluster randomized controlled feasibility trial (Thomas et al., 2015; Thomas et al., 2011). The SVP comprised assessment, conservative interventions, and review. Assessment includes a 3-day bladder diary and comprehensive continence assessment (Thomas et al., 2015). Patients who are cognitively able receive bladder training which aims to promote continence (Wallace, Roe, Williams, \& Palmer, 2004); those with cognitive impairment receive prompted voiding which aims to minimize incontinent episodes (Eustice, Roe, \& Paterson, 2000). Progress is reviewed weekly with change from prompted voiding to bladder training if cognitive ability improves.

Four services randomized to the Supported Implementation arm of the trial introduced the SVP using an implementation strategy, facilitation, to assist the process of embedding into practice. Facilitation involves supporting and enabling people to change their practice (Cheater et al., 2006; Harvey et al., 2002). It involves guiding the group toward accomplishing a goal, helping members identify obstacles that may impede progress and enabling them to identify strategies to overcome them (Stetler et al., 2006).

We have published the results of the case study phase of the trial (Thomas et al., 2014) and the trial itself, including other elements of the process evaluation (Thomas et al., 2015). The main trial included a qualitative assessment of feasibility from the perspective of multiple stakeholders. We chose the normalization process theory (NPT) as a suitable framework to capture implementation processes and consequences for working practices and professional responsibilities (May et al., 2007; May et al., 2009). The framework is designed to facilitate understanding of the practical issues involved in embedding complex interventions into routine practice, for example, ease of use and integration, and has been used in a range of settings. A recent systematic review of 


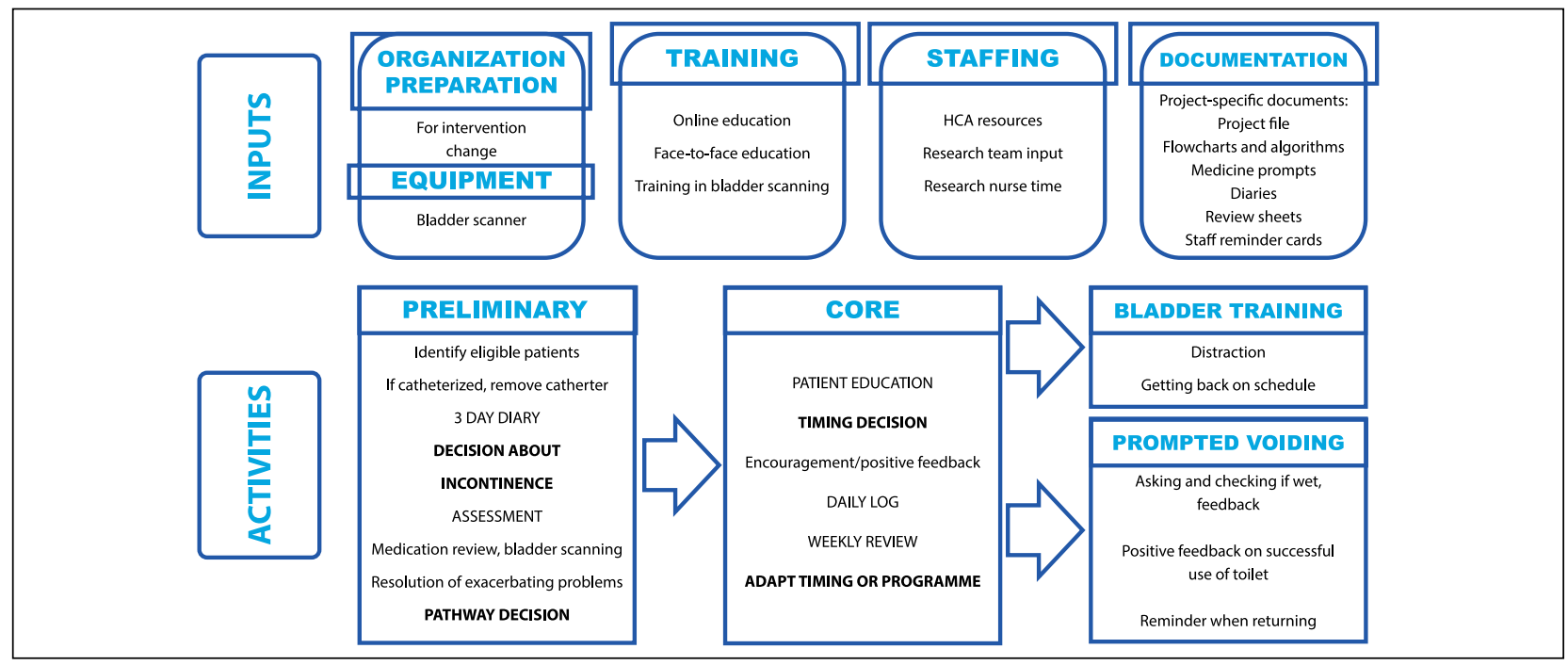

Figure I. Inputs and activities associated with SVP implementation. Note. SVP = systematic voiding program; $\mathrm{HCA}=$ health care assistant.

studies using it supports its ability to explain implementation processes (McEvoy et al., 2014). Our intervention provided a good fit with Mays' definition of complex interventions as comprising "multiple behavioural, technological, and organizational components" (May et al., 2007). In addition, the framework's view of change as resulting from collective, rather than individual, action (May et al., 2007) was in line with our aim of bringing about change through group activity. It has 16 dimensions in four main categories of

a. Coherence: The sense-making work that people need to do individually and collectively about the meaning, use, and utility of a new practice;

b. Cognitive participation: The shared work that people need to do to build and sustain a new practice;

c. Collective action: The operational work that people do to enact a new practice, including whether people are able to do what is required of them, whether they have trust in each other, and the necessary skills and resources;

d. Reflexive monitoring: The appraisal work that people do to assess and understand the ways in which a new set of practices affect them and others around them.

We aimed to assess feasibility and inform future trial design by using the NPT framework to

- explore the views of staff on embedding the SVP in practice;

- identify features in the organizational context that influence implementation;
- develop explanations for how the SVP affects patient outcome.

\section{Method}

We conducted a multi-site qualitative process evaluation component using normalization process theory as a framework, in line with U.K. Medical Research Council guidelines recommending theory use for complex intervention design and evaluation (Medical Research Council, 2008). Other components of the process evaluation are reported elsewhere (Thomas et al., 2015).

\section{Setting, Site Recruitment, and Trial Inputs}

We recruited eight National Health Service (NHS) stroke services in England and Wales to the intervention arms of a cluster randomized controlled feasibility trial of SVP implementation via the national Stroke Research Network. We required stroke services to have access to appropriate excess treatment (the difference between the cost to the U.K. NHS of providing the new treatment and the cost of standard treatment) and service support costs (additional patient care costs associated with the research which end once the study has stopped; Department of Health, 2012) to be enrolled in the trial, and all services in the trial (including sites in the usual care arm) were given an additional 2.8 whole time equivalent health care assistants (HCAs). All nursing staff employed in the intervention units had access to an education program (delivered online and in person). Research nurses additional to the ward staffing complement were involved in recruitment, scheduling, and data collection on all units. Figure 1 summarizes inputs 
to the stroke service in terms of resources, training, and personnel, provided as part of the trial.

\section{Details of the Trial Intervention}

Nurses using the SVP undertook a continence assessment based on history taking and completion of a 3-day bladder diary and delivered an individualized program tailored to the type of incontinence and the cognitive ability of the patient. The SVP had two possible routes: bladder training for those people who were cognitively able and prompted voiding for those with cognitive impairment.

The program included weekly review of patient progress by registered nurses and adjustment to the voiding interval or change of route as appropriate. The purpose of the weekly review was to assess patients' progress through review of daily clinical logs recording all continence activities and incontinent episodes over the past week. They provided an opportunity to assess if the patient was on the correct regime, and to adjust the voiding interval up or down if the patient was progressing or not progressing, respectively. Clinical staff were encouraged to involve patients and/or their carers in the review if at all possible.

In addition to recruiting patients who were incontinent on assessment, we recruited patients with catheters into the trial and started the SVP on removal of the catheter. Figure 1 also summarizes the nursing activities associated with SVP delivery.

\section{Subjects and Sampling}

We included nurses or clinical leaders in the evaluation if they had a role in delivering or managing the delivery of the SVP. We selected staff for interview purposively at each site to ensure representation from HCAs (both ward and trial funded); registered nurses involved in assessment and SVP program planning for individual patients; and ward managers. Researchers contacted staff to ask if they might be willing to participate in interviews. Because sites were geographically distant, we arranged interviews with staff providing informed written consent on a group or individual basis depending on the preference of the participant(s), and time available.

Trial approval was granted by Bradford Research Ethics Committee (Reference number 10/H1302/60) and local Research and Development departments in the participating hospital Trusts and Health Boards (providers of secondary health services in England and Wales).

\section{Data Collection}

We undertook semi-structured interviews with groups or individuals exploring their experiences of SVP implemen- tation. Interviews were chosen to investigate complex processes which may not be conscious, or thought about without prompting. Interview items were developed aligning with the 16 dimensions of the NPT framework described above.

The trial coordinator conducted interviews between the middle to the end of the intervention period of the trial (Month 6 onwards of a 6- to 9-month intervention), so that implementation processes were readily recalled. Interviews were held in a private setting within the ward environment such as the office or a meeting room, and lasted 30 to 60 minutes on average. We digitally recorded interviews with the permission of participants.

\section{Data Analysis}

We transcribed interviews verbatim, then two people coded independently using a directed content analytic approach (Hsieh \& Shannon, 2005) drawing deductively on the main dimensions of the pre-specified NPT framework and using a coding framework including operational definitions for each dimension and sub-dimension. Directed content analysis is designed to validate, or conceptually extend, an existing theory (Hsieh \& Shannon, 2005). Evidence is presented for each dimension using examples and descriptive evidence with little analytic transformation of the data. After refinement of the coding framework, internal consistency of coding remained high, with no differences between coders in allocation to the four main NPT dimensions. Initially, we constructed interview summaries using the NPT coding frame. Then, we created site summaries across all respondent interviews from one stroke service by condensing down to remove overlap and redundancy, while keeping as closely as possible to original wording and including the number of respondents making a similar point. We paid careful attention to similarities and differences across the data set, for example, between registered and unregistered nursing staff. Finally, one researcher collated an across site summary for each NPT dimension populated with direct quotes from respondents to illustrate meanings. A second researcher then checked the original transcripts to ensure that the meaning of quotes used had been maintained, and to verify the number of sites supporting a statement.

We checked the number of quotes used per site, to ensure sites were equitably represented in the interpretive analysis. Divergence of views could be lost to some extent in site summaries (Benzer et al., 2013; for example, if a particular grade of staff was dominant in group interviews), so we compared findings from interviews with registered and unregistered nursing staff, and for sites in the intervention only and intervention plus supported implementation trial arms. An external member of the project team with experience of using the NPT framework in other 
Table I. Number and Grades of Staff Interviewed per Site.

\begin{tabular}{lcccccccc}
\hline & \multicolumn{7}{c}{ Site } \\
\cline { 2 - 9 } Grade of Staff & A & B & C & E & F & H & K & L \\
\hline $\begin{array}{l}\text { Ward manager } \\
\text { Sister/charge nurse }\end{array}$ & I & I & I & 2 & I & I & I \\
Staff nurse & & I & I & I & I & & 2 & 2 \\
Research nurse & I & & & & & & & \\
Healthcare assistant & 2 & I & & 3 & 2 & 2 & 3 & 4 \\
Number of interviewees per site & $\mathbf{4}$ & $\mathbf{3}$ & $\mathbf{2}$ & $\mathbf{7}$ & $\mathbf{5}$ & $\mathbf{5}$ & $\mathbf{6}$ & $\mathbf{6}$ \\
Number of interviews per site & $\mathbf{4}$ & $\mathbf{3}$ & $\mathbf{2}$ & $\mathbf{5}$ & $\mathbf{3}$ & $\mathbf{5}$ & $\mathbf{4}$ & $\mathbf{6}$ \\
\hline
\end{tabular}

research studies undertook external review of consistency of interpretation of the data. We did not feed back summaries to the sites, because of the possibility that individuals' viewpoints could be identified. Audit trail processes included maintaining a coding diary for the NPT framework and coding checks between analysts on all transcripts.

We identified possible mechanisms of action by looking across the whole data set for the attributions staff made for any changes in the processes or outcomes of care. For example, the following statement "I could see it had a positive effect on quality-of-life and discharge destination and for that reason I liked it" identified visibility of patient outcome as a potential mechanism influencing nursing staff perceptions and motivation to maintain the SVP.

\section{Presentation of Findings}

We present findings for the four NPT categories, with illustrative quotes. Single numbers in brackets identify the number of sites supporting a finding. Each quotation has a participant grade (RN for registered nurses, HCA for health care assistants, and WM for ward managers). The main aim of using the NPT framework was to identify factors in the implementation of the SVP which might have influenced the success of the program in terms of improved processes (e.g., good uptake), or better outcomes (e.g., reduced incontinence, less cost). We summarize findings in each NPT category as barriers or enablers to implementation. Finally, we summarize the main mechanisms of action suggested by the findings (i.e., the different potential ways the SVP might produce a change in outcome). The research team as a whole built implications for a future trial from these mechanisms during Trial Management and Steering Group meetings.

\section{Findings}

\section{Demographic Data}

We summarize demographic data for the interview respondents in Table 1. We interviewed 38 members of staff in total, during 32 interviews.

\section{NPT Categories}

Coherence. Coherence refers to whether a new practice is different from what people were doing before, and whether they understand it, agree with it, and recognize its potential benefit. Sites differed in how much continence care they were providing prior to introducing the SVP: four were doing very little, and four had regular toileting schedules in place. Respondents commented that the SVP was more structured and formal (5), timed (4), and documented (8) than what happened previously. Program components were seen as logical, "It's a thorough assessment to begin with, and then you plan the interventions you're going to take, and then there is an evaluation as well, so it does seem a good circle of events" $(\mathrm{RN})$, and understandable, "It's not rocket science. It's actually quite a simple process." (RN, WM)

There was evidence that some staff did not necessarily differentiate between the SVP and regular toileting (3), "We had quite a lot of dissent toward it [the SVP]. Whether people didn't fully understand what we were trying to do or just thought, 'Well, we already do this, do we need to go down this avenue?"' (RN). The understanding of certain staff groups was also questioned, including HCAs, "I don't think the auxiliaries understood for about the first half of the program that there was a process. It was just 'Here's ICONS [name of trial]', and they're put on prompted voiding" (RN); and bank staff (a pool of nurses and HCAs in the United Kingdom who cover wards requiring extra staff on a temporary basis) because of their lack of training and experience with the SVP. Staff thought that most patients understood the SVP to an extent (3).

Most respondents agreed that the overall aim of the SVP was promoting continence as part of the nursing role, and a component of rehabilitation (6). They viewed the SVP as increasing the priority of continence care (5), and highlighting to nurses that incontinence is amenable to change (3). There was acknowledgment of the importance of continence for patients (4), particularly in relation to community living, quality of life, and discharge destination (3). Other potential benefits for patients included 
increasing comfort, improved self-esteem and dignity, and avoiding embarrassment and the adverse effects of incontinence. Another commonly cited benefit (3) was in some rebalancing of control between patient and staff, "As nurses, you tend to do everything, so this is a way of giving the patient back ownership and getting them to start clicking in" (RN, WM). Staff recognized that continence control signals wider recovery from stroke (2) and gives the patient hope (4). This also linked to nurses believing that they could help patients (4), with the SVP giving nurses an increased therapeutic role, "I think patients on the program felt quite secure, they knew they were incontinent and they knew that we were addressing the situation, and that there was a plan to try and help them" (RN). Staff also identified potential benefits for themselves: providing them with structure and guidance (6), making them think more about continence (3), and reducing workload in the long run (3).

Although staff could see potential benefit, the added work was unpopular (3) and most sites (6) were quite negative about the paperwork, particularly the assessment. Respondents also disagreed about the suitability of the SVP for some patient groups specified in the inclusion criteria (3), especially those who were unwell, people with dementia, or long-term continence problems, "I couldn't understand why some patients with catheters were signed up for ICONS. That was where our sticking point was, wasn't it; it was the long-term prostate problems and ladies with long-term catheters" (RN). Overall perception of the value was summarized by one respondent as: "It's definitely better for the patient, but it does take more work and that was the biggest thing" (RN). Table 2 summarizes barriers and enablers to coherence.

Cognitive participation. For a new practice to be adopted, key people need to drive it forward, staff need to believe that it should be part of their work, and they need to be able to organize themselves to incorporate the new practice into ward routines and procedures. Senior ward staff were seen as pushing the new practice forward (8) by promoting the program, providing direction and reminders, education and supervision, organization and delegation, and monitoring and feedback. Ward managers commented on the key role of proactive senior staff nurses in three sites, ". . . we've also got some of the more senior staff nurses who are really confident in delivering the same sort of thing: they were the ones who initiated in governance meetings what we needed to do." (RN, WM). The perspective provided by external research nurses was valued (6), for coordination, monitoring performance, or to counteract established perceptions, "People you wouldn't think would be a candidate; somebody from the outside would come in and say to us give it a go and see how they do. And yes they did well." (RN, WM)
Ward managers and registered nurses in four of the eight sites thought their staff were on board with the program, or at least not negative. Staff attributed willingness to be involved to enjoyment (1), a decrease in workload in the long run (1), or wanting to be involved in the research (2). Three sites reported that there was quite a lot of dissent in the initial stages, and that it took time to get the program going, get people on board, and keep them motivated. Respondents from two of these sites went on to say that once staff had been involved, they realized that the SVP did not require much extra work. Facilitators to enrollment included whether staff saw that the program could be done, and their experience of success. Whereas the staff thought most patients were quite happy to be involved (4), some were not, possibly because it might extend the hospital stay, "I think maybe they're a bit worried that going on the program will prolong their stay. They want to get out of hospital as quickly as possible and go back home" (HCA); or because it drew attention to incontinence, "I think it might be drawing attention to their problem as well. Sometimes in the early stages they've got so much else going on its making them focus on another problem." (RN, WM)

The SVP itself was not seen as technically complex, but staff recognized that it needed embedding into the ward routines or it was in danger of being forgotten. Prompting mechanisms included use of care clocks to help remind staff about the timing of toileting (1), and leaving reminder notes in diaries for weekly reviews (1). All the sites had undertaken activities to incorporate the SVP into the ward routines and procedures, including having symbols on the ward whiteboard (wipe-clean boards enabling clinical staff to communicate information about individual patients) and on individual boards behind the patients' beds to discretely remind staff who was on the SVP. The handover charts (sheets containing information relevant to the patient including outstanding tasks required to manage their care) were used to record which stage of the SVP patients had reached. Completing the paperwork for the SVP had to compete with other tasks for attention, "It was really hard to keep vigilant about ICONS because it was getting lost within all the other paperwork ... It needs to be visual" (RN, WM), and staff recognized it was not always completed.

During the period when the SVP was operating, intentional rounding (Bartley, 2012) was introduced into the U.K. NHS with the aim of ensuring that all patients were seen by staff on a regular basis to meet essential needs, including fluid intake, skin care, and toileting. This worked in favor of the SVP because staff were required to pay attention to the toileting needs of all patients on a regular basis, "The PRONE initiative [intentional rounding] made it easier with ICONS because people were looking at charts every two hours anyway" (HCA). 
Table 2. Barriers and Enablers to SVP Implementation.

\begin{tabular}{|c|c|c|c|c|}
\hline NPT Domain & Barriers & Sites Endorsing & Enablers & Sites Endorsing \\
\hline \multirow[t]{9}{*}{ Coherence } & $\begin{array}{l}\text { SVP not seen as different to } \\
\text { regular toileting }\end{array}$ & 3 & $\begin{array}{l}\text { Some sites already had regular } \\
\text { toileting in place }\end{array}$ & 4 \\
\hline & Extra work & 3 & SVP seen as structured & 6 \\
\hline & Paperwork disliked & 6 & SVP increases priority of continence & 5 \\
\hline & \multirow[t]{6}{*}{$\begin{array}{l}\text { SVP seen as unsuitable for some } \\
\text { patient groups }\end{array}$} & \multirow[t]{6}{*}{3} & $\begin{array}{l}\text { Incontinence seen as amenable to } \\
\text { change }\end{array}$ & 3 \\
\hline & & & $\begin{array}{l}\text { Rebalances control between staff and } \\
\text { patient }\end{array}$ & 3 \\
\hline & & & $\begin{array}{l}\text { Continence control signals recovery } \\
\text { to patient }\end{array}$ & 2 \\
\hline & & & Increases nurses' therapeutic role & 4 \\
\hline & & & Encourages thinking about continence & 3 \\
\hline & & & Reduces workload in the long run & 3 \\
\hline \multirow[t]{5}{*}{$\begin{array}{l}\text { Cognitive } \\
\text { participation }\end{array}$} & \multirow{5}{*}{$\begin{array}{l}\text { Takes time to get people on } \\
\text { board } \\
\text { Patients fear extended hospital } \\
\text { stay and drawing attention to } \\
\text { problem } \\
\text { Paperwork could be forgotten }\end{array}$} & & $\begin{array}{l}\text { Senior staff seen as key to driving the } \\
\text { new practice }\end{array}$ & 8 \\
\hline & & & $\begin{array}{l}\text { Research nurse identified as a valuable } \\
\text { resource }\end{array}$ & 6 \\
\hline & & & $\begin{array}{l}\text { Enjoyment and reducing work helped } \\
\text { staff engage }\end{array}$ & 4 \\
\hline & & & Not much extra work required & 2 \\
\hline & & & Use of reminder systems & 8 \\
\hline Collective action & $\begin{array}{l}\text { Maintaining surveillance for } \\
\text { screening } \\
\text { Difficulties with diary } \\
\text { completion over } 3 \text { days } \\
\text { Some patients dislike regular } \\
\text { prompting } \\
\text { Repeatedly asking about } \\
\text { wetness disliked } \\
\text { Distraction/delay challenging for } \\
\text { staff and patient } \\
\text { Timing difficult to schedule, } \\
\text { remember, adhere to } \\
\text { Weekly reviews can be } \\
\text { forgotten } \\
\text { Extra work }\end{array}$ & 7 & $\begin{array}{l}\text { Extra staff facilitated consistent care } \\
\text { Improved skill/confidence in managing } \\
\text { continence } \\
\text { Positive impact on continence-related } \\
\text { interactions }\end{array}$ & 8 \\
\hline \multirow[t]{4}{*}{ Reflexive monitoring } & SVP not suitable for all patients & & Benefits for patients & 8 \\
\hline & \multirow{3}{*}{$\begin{array}{l}\text { Senior staff found the SVP hard } \\
\text { to monitor }\end{array}$} & & Benefits for staff & 6 \\
\hline & & & $\begin{array}{l}\text { Visible success is important for } \\
\text { motivation }\end{array}$ & 4 \\
\hline & & & $\begin{array}{l}\text { Change in patient progress and } \\
\text { outcome reflected in paperwork }\end{array}$ & 5 \\
\hline
\end{tabular}

Note. SVP = structured voiding program; NPT = normalization process theory.

Conversely however, it could also work against implementing the SVP as an individualized timing regime, "When we're going back doing the rounding which is done on a two-hourly basis we'll ask as well, 'Do you want the toilet?' so we try tying the two together." (HCA) Table 2 summarizes barriers and enablers to cognitive participation.

Collective action. New practices require staff and patients to interact differently, and to do different things. To be successful, people have to have the skills, resources, relationships, and confidence to do the tasks required. There were four main points in the SVP where any difficulties in carrying out the SVP would be evident including decisions about eligibility, pathway, timing, and adaptations.

Making a decision about eligibility. In the preliminary stage of the SVP, ward staff had to "maintain vigilance" about eligibility as new patients were admitted, "It's just being vigilant on top of patients coming over to us and are they 
accounted for on ICONS, are they somebody you could do it with?" (RN, WM). Staff needed to maintain the SVP at different time points for each patient and it could be difficult for them to keep the SVP in mind over time,

The patient goes backwards and forwards - catheterized, not catheterized, starts the program, goes into retention, is re-catheterized, comes back, starts the program again. This can happen a few times ... they're the ones that can be easily left. (HCA)

The SVP paperwork did not provide a way of managing this "surveillance" activity for each patient and it generally fell to senior ward staff to monitor progress and prompt the completion of a bladder diary for new patients. Staff in acute wards questioned diary completion over 3 days, "The three-day diary is a bit too long to be assessing people when they could be at risk of excoriation. I would rather start two-hourly prompting earlier" (RN, WM). Patient transfer between acute and rehabilitation wards also caused problems with continuity of diary completion over 3 days:

If part of the diary is being done on the acute unit we didn't know whether to start again. We started again because we didn't know whether it was reliable, because it was only part done, or done too early. (RN, WM)

Making a decision about the pathway. Prompted voiding was the most common option, not necessarily just for people with cognitive problems, but for everyone, "We start off with prompting and then bladder training for the people who are cognitively okay" (RN). Many of the conditions commonly affecting patients after stroke presented challenges to managing a prompted voiding regime, such as depression, fatigue, immobility, communication problems, urge incontinence, and agitation:

There were a couple of patients that we started on the program and we stopped it because they have such huge problems, they were confused. I think they just got to the point where every time you asked them to go to the toilet they were getting very angry, frustrated, so we just backed off because it was distressing them ... I think maybe it was the frequency that they couldn't deal with, the last thing they remembered was you asking them to go to the toilet, and here you were again. $(\mathrm{RN})$

Repeatedly having to ask if the patient was dry or wet was also disliked.

Bladder training was not used as frequently as prompted voiding. Comments suggest that the principle of extending the voiding interval by small increments in bladder training might have been misunderstood but also illustrated how difficult it was to practically manage the principles of distraction and delayed voiding in a stroke unit,

Very agitated patients who want to go to the toilet every five minutes, I feel a bit awkward saying you've been now and you got two hours to go, it feels a bit hard. I do tell them and then they get anxious more and more and get quite irate so you've got to give them a bottle. You keep them calmthey've already had one stroke you don't want them to have another. (HCA)

Respondents from two sites commented that it looked bad to relatives when staff appeared to be stopping people from going to the toilet.

Making a timing decision. For bladder training or prompted voiding, staff had to choose a timing interval (the time span between voids), based on the bladder diary. Individualized timing was the most commented on aspect of the SVP because it could be difficult to schedule, remember, and adhere to, especially in relation to therapy, visiting times, or mealtimes. The program timings set up expectations between staff and patient, which could have negative consequences, "That's one thing you must remember to do if you've promised that you're going to come back, you must go back" (RN, WM). Nurses identified strategies to keep to timings, such as using care clocks, or enrolling patients to remind staff, "We make sure they've got the buzzer and say 'Right, we're due to come back at such a time, if you press $10 \mathrm{~min}$ utes before then we're not leaving you on the last-minute," $(\mathrm{RN}, \mathrm{WM})$.

Adapting the timing or program. The SVP protocol suggested reviewing patient progress at weekly intervals using the daily treatment logs and a 7-day bladder diary completed by the patient. Completing a bladder diary seemed useful for those patients who could manage it,

Those people who went on bladder training quite enjoyed being in charge of their piece of paper and their pen. It was something that they felt they had some control over in this environment where everything is so completely different. (RN)

Despite placing reminders in the diary, weekly reviews could be forgotten. Staff were aware of the consequences of not reviewing timing, "It didn't matter if people didn't change very much but there is the chance that you might have missed a couple of weeks where somebody might have moved a lot faster if you'd got the assessment done on time" (RN). Two sites suggested scheduling weekly reviews at the weekend in line with reviews of other aspects of care. 
As the SVP became an accepted part of ward practice, staff gained more confidence in their own knowledge of continence, including awareness of the potential for intervention, "Nurses are more aware that continence doesn't have to be a big problem if you can get it in the early stages" (RN, WM); greater technical skill, "The bladder scanning was a skill we never had before, it's a skill we've got now, continue to use" (RN); and ability to talk to patients about continence, "Because we have more knowledge we were having more informed conversations with patients" (RN, WM). Respondents reported improved interaction between nurses and patients (4), between nurses (2), and with the wider multidisciplinary team (3) about continence, although one respondent thought that the SVP might have had some adverse impact on ward relationships:

There were negative interactions because of it. The auxiliaries were in high demand, quite rightfully overstressed regarding it, and it did cause some bad morale and some bad attitudes on the ward, but I think they were resolved further down the line and things began to work better. (RN)

All eight sites said that having extra staff helped, "With three extra staff. .. We thought we'd died and gone to heaven" (RN). Extra staffing meant that staff could deliver the program consistently, "If you were caught up with something else perhaps you couldn't get back there to make sure there was consistency. The extra staff made sure you could follow it through" (RN). However, having extra staff did not seem to affect perceptions that workload had increased. Seven out of eight sites commented on the extra work of the program on what were already busy wards, six identified inadequate staffing as a barrier to delivering the program, and five identified problems with staffing shortages during the program delivery period. Adequate staffing appeared to be important in whether staff felt positive about the program, "The program has worked generally as long as we've got enough staff to make sure that all the paperwork is done, and chasing it up-I think it's good" (RN). Table 2 summarizes the barriers and enablers to collective action.

Reflexive monitoring. For a new practice to be sustained, people have to be convinced of its benefits more than costs. Staff from five sites said they could see change in the patients' progress and outcome reflected in the paperwork:

Once they started noticing a lot of the patients we did get them triggered back into timing and it was only as you were discharging and having it in paperwork, the fact is we got them into a routine and it makes a big difference. ( $\mathrm{RN}, \mathrm{WM})$

The structure provided by the program was identified as motivating (1), as was experience of success (3), "It's all down to education, confidence, and knowing the result of it really, knowing that it's going to work" (RN). Visible success was important for staff motivation, "We did have some success stories over an 18 month period. As auxiliaries started to realize and started seeing more of the benefit because they weren't constantly going back to these patients it did become more popular over time" $(\mathrm{RN})$. Feedback from the family was also influential, "It's when the family start saying oh she's continent now, that made the difference that started people thinking" (RN, WM).

Respondents identified that patients felt better, physically and emotionally (5), with benefits for self-esteem, independence, and dignity of the patient (3). More involvement, ownership, and control of the patients' recovery (5) improved their confidence, "Patients are getting self-esteem and confidence in themselves because they are getting back to their normal ways like they would at home" (HCA). One respondent thought this helped patients believe that their needs were being met, "We are pre-empting what might be coming by addressing needs on a regular basis, patients feel their needs are being met" (RN, WM).

Benefits for nurses and nursing care included increased nursing awareness, knowledge or confidence (6); making nursing care easier, reducing workload (5); reduction in pad use (5); improved communication with patients and relatives (3); improved communication between staff (2); changing nursing attitudes to incontinence (3); increased therapeutic role for nursing (2); changes to care planning (3); increase in use of bladder scanner (3); reduction in catheter use (2); calmer ward, reduced use of call bells (2); and increase in investigations (1). However, some staff remained less enthusiastic than others, "It was explained well enough but it was whether the staff took it. Here's something else for us we've got to do again" (RN).

Senior staff said that they found the program hard to monitor, but also informally noted changes, "Just watching and seeing what's happening on the ward such as less use of resources, less wet beds, less wet clothes, less nursing time, less buzzers going off' (RN, WM). Although the SVP appeared to influence the amount of monitoring of continence, "I suppose we are monitoring their continence more closely, that gives us a better picture" (RN), respondents recognized that linking the SVP to improved continence outcomes was challenging, "It's difficult to say whether people who have been successful on ICONS might have been successful anyway" (RN, WM).

Respondents felt the program was better than previous continence practice, conditional on having the staff to do it. All eight sites reported that the intervention worked for a proportion of people, "It has promoted continence in lots of people so ultimately it is good ... I think you can see that it works" (RN), with some attempting to put a 
figure on the proportion, "I'd say they made improvements about $75 \%$ of the time" (HCA). There was a degree of surprise about the perceived effectiveness of the intervention from both registered staff, "What we do now is better-no question. I've been surprised, I think it has worked" (RN, WM), and non-registered staff, "I got a bit upset at first, it was like here we go again, but this time I've actually seen a few benefits" (HCA).

There was general agreement (8) that some patient groups tended to do better, "It worked for patients with less cognitive impairment, more mobility, better communication and understanding, younger people" (RN). However, two respondents pointed out that it could also work for people with cognitive difficulties, and one speculated about the reasons:

Sometimes the ones with cognitive impairment were the ones that respond better to the routine. In some ways it helped the ones that were more cognitively impaired ... who are quiet and withdrawn and don't demand attention-it gives them attention. $(\mathrm{RN})$

All respondents identified patient groups that were not suitable for the SVP, including those with continuous leakage, unwell patients, the frail elderly, and people with lack of sensory awareness. There was a fairly general view (4) expressed that the program did not work with some patients. Respondents attributed non-response to pre-existing incontinence or lack of awareness (3), or cognitive problems (3), but thought that response was to some extent unpredictable:

Some it didn't have any impact on at all. You couldn't get any pattern or rhyme or reason to what was happening. It wasn't a particular type of patient, it was variable; it depends on the mental capacity, the cognition — but it could vary even with that. (RN)

One respondent said, "But it's a fact that sometimes you do have to implement it to see does it work?" (RN)

Staff at five out of eight sites identified that they were still doing the physical components of the SVP after the trial intervention period, at least in terms of regular toileting. Only one site suggested that the SVP was not continuing, with some expressed regret:

It probably wouldn't be a popular decision to carry it on but personally I think it's a shame it has stopped. Since the trial is finished it's not in place anymore. We manage it with nappy pads like we did before. Some patients have been encouraged to use urinals and bedpans as much as they can. There is no formal assessment in place anymore. $(\mathrm{RN})$

However, despite this overwhelmingly positive evaluation of the impact of the SVP and its continuation in some form in more than half of the sites, even without extra staffing, this was not unconditional, per protocol, or wholesale. Respondents said that staffing levels would affect whether the program was continued (4), toileting was to be merged with skin and safety rounds (2), and the paperwork would not be continued in its present form (4). In two sites, the program was continued, but only with those patients thought likely to succeed.

\section{Discussion}

Our aim in the NPT evaluation was to identify factors affecting the success of SVP implementation, and potential mechanisms linking SVP processes with outcome. The findings were based on interviews with varied grades of nursing and care staff in eight stroke services involved in implementation of the SVP in a feasibility trial in the United Kingdom. No comparison with usual care sites was possible; as these sites did not implement the SVP, they could not be asked about the embedding process.

Our data were coded directly using the headings of the various NPT constructs and components. This approach could be criticized for pre-determining the analysis, however May et al. would argue that the data still need to be subject to critical analysis and interpretation of the content and significance of the data (http://www.normalizationprocess.org). In our study, this involved taking into account the numbers of sites endorsing a particular viewpoint, and further analysis to determine potential mechanisms of action of the SVP.

Despite the provision of additional staff as part of the research, workload and staffing were the most commonly stated issues influencing the workability of the intervention, in line with studies implementing UI interventions in other settings (e.g., Beck et al., 2005). This is perhaps not surprising with an intervention which requires physical effort and unremitting attention. The second most commonly mentioned barrier was the paperwork-particularly the continence assessment, which was perceived to be overlong. Difficulties with scheduling and timing of continence care in a rehabilitation setting, and carrying out distraction and delayed voiding with patients after stroke, perceived lack of suitability of the SVP for some patient groups, and patient fear of extending hospital stay were also identified as potential barriers. Senior staff found the program hard to oversee, and staff from acute units had more difficulty prioritizing continence.

Staff perceived that regaining control of continence empowered patients, and gave them hope for other aspects of stroke rehabilitation as originally hypothesized by Barer (1989). Staff were motivated by being able to see progress, success, and the longer term reduction in workload. Monitoring, coordination, and support from senior staff, use of reminder systems, introduction of intentional rounding, and patient and relative involvement also helped implementation. 
Table 3. Potential Mechanisms of Action Influencing Care Processes and Outcomes.

\begin{tabular}{|c|c|c|c|}
\hline \multirow[b]{2}{*}{ Potential Mechanisms } & \multicolumn{3}{|c|}{ Changes in Care Processes and Outcomes } \\
\hline & Increase in Priority & Increase in Ownership & Different Care \\
\hline Consistency of care & $\begin{array}{l}\text { Altered perceptions- } \\
\text { incontinence seen as } \\
\text { amenable to intervention }\end{array}$ & $\begin{array}{l}\text { Nurses more skilled in discussing } \\
\text { and managing continence } \\
\text { Increased involvement and training } \\
\text { of health care assistants } \\
\text { Pride in therapeutic role, enhanced } \\
\text { nursing role in multidisciplinary } \\
\text { team }\end{array}$ & $\begin{array}{l}\text { Extra staff, able to deliver } \\
\text { consistent care } \\
\text { Nurses more proactive in } \\
\text { intervening in continence } \\
\text { problems } \\
\text { Role clarity, improved staff } \\
\text { communication, and planning }\end{array}$ \\
\hline $\begin{array}{l}\text { Individualization of } \\
\text { care }\end{array}$ & & $\begin{array}{l}\text { Increased patient knowledge, } \\
\text { involvement, ownership, control } \\
\text { Increased relative involvement }\end{array}$ & $\begin{array}{l}\text { More assessment, scanning } \\
\text { Regular toileting, more attention } \\
\text { Perseverance with individual } \\
\text { patients }\end{array}$ \\
\hline $\begin{array}{l}\text { Visibility of care } \\
\text { processes and } \\
\text { outcomes }\end{array}$ & $\begin{array}{l}\text { Ward manager or research } \\
\text { nurse as driver, coordinator, } \\
\text { champion } \\
\text { Staff are reminded, monitored, } \\
\text { supported }\end{array}$ & $\begin{array}{l}\text { Seeing the benefit, aware of wider } \\
\text { consequences, longer term } \\
\text { outcome } \\
\text { Seeing that the SVP cuts workload }\end{array}$ & $\begin{array}{l}\text { Maintaining vigilance, recruiting to } \\
\text { SVP, keeping SVP in mind over } \\
\text { time } \\
\text { Trying the SVP with everyone, so } \\
\text { more/different people receive care }\end{array}$ \\
\hline
\end{tabular}

Note. SVP = structured voiding program.

The findings identify barriers and enablers specific to the process of implementing behavioral treatment for UI in acute stroke rehabilitation settings, some of which resonate with other research. In acute care, Dingwall and McLafferty (2006) also identified conflicting clinical priority as a barrier to promoting continence. In U.S. longterm care settings, elderly people prioritized being able to independently manage continence to avoid dependence on nursing staff for toileting assistance (Johnson, Ouslander, Uman, \& Schnelle, 2001). As well as identifying the unique combination of barriers and enablers specific to this UI intervention (behavioral), client group (stroke recovery), and context (early rehabilitation), our purpose in using NPT as a framework was also to understand how people act and react in complex, constrained conditions. NPT tries to understand the social and cognitive processes, or "social mechanisms" involved in implementing new complex interventions (May, 2013).

Table 3 summarizes three potential mechanisms associated with the logical structure and organization of care provided by the SVP: consistency, individualization of care, and visibility of care processes and outcomes. The diagram summarizes changes in staff or patient understanding, participation, action, and evaluation extracted from the findings in three main areas of impact: increased priority for continence care, increased ownership of continence care, and different care provision.

\section{SVP Enables Consistency of Care}

A major strength of the SVP appeared to be that it facilitated consistency of care. It gave focus and knowledge of continence management to staff and patients, in a structured format that was logical, organized, and documented. With the provision of adequate staff, care could be delivered consistently each day, and over the whole trajectory of the patient's recovery. Staff and patients worked together on the same plan, and people had role clarity and continuity of purpose for continence assessment and management (although this did not work as well across the transfer between acute and rehabilitation units). The structured and documented format of the SVP was also very accessible to HCAs, giving more meaning and value to a major component of their daily activity. The provision of evidence-based guidelines and educational materials to improve nursing competency in continence care has been used previously to improve care in outpatient and primary/community care settings (Campbell, Knight, Benson, \& Colling, 1991; Cheater et al., 2006; Sampselle et al., 2000; Williams, Crichton, \& Roe, 1997), but not previously in acute care. Structured assessment and management of care in stroke has been used to improve continence outcomes in rehabilitation settings (Wikander, Ekelund, \& Milsom, 1998).

\section{SVP Promotes Individualization of Care}

There is strong evidence in the findings that care delivery changed. More care was delivered because staff were proactive in intervening, and patients were getting more continence-related attention. Increased vigilance about continence meant that structured UI care was provided to a wider group of patients than previously, and staff persevered for longer with individual patients. Staff had a heightened awareness of continence and the potential for 
improvement in patients thought unlikely to benefit: They talked about being surprised at good outcomes.

Individualization of the SVP was probably the most difficult aspect for staff to carry out and the mechanism least supported by the findings, which suggested some lack of differentiation between regular toileting and the SVP. There was evidence that staff were individualizing care to some extent, but it was also evident that this aspect of the SVP was not carried out according to protocol. Formalizing nursing care in recording processes may obscure how nurses really act to individualize care; this was not addressed by the NPT framework so whether this occurred is unknown. These issues, together with the linking of the SVP with intentional rounding (Bartley, 2012), means it is unclear if the mechanism of individualized care contributes more to improvement in outcome than consistency of toileting assistance. Policy-driven changes such as intentional rounding (Bartley, 2012) could have the unintended consequence of the adoption of a "one size fits all" voiding schedule, rather than individualized voiding plans tailored to patients' patterns of incontinence.

\section{SVP Promotes Visibility of Outcome}

A strong theme in the findings was staff talking about seeing the benefits of their intervention. They saw improvement in individual patients' continence, and they also saw the trajectory of improvement in the paperwork. The paperwork allowed staff (particularly the HCAs) to see progress over time and to attribute it to their effort to deliver consistent care. Patients and relatives were also more aware of continence, and staff were conscious of their expectations. Family members of people in nursing homes are aware of improvements in incontinence care (Levy-Storms, Schnelle, \& Simmons, 2007), and whereas family are acutely aware of failures in continence care in acute settings (Booth, 2013), their involvement can also have positive impact. Being able to link the effect of nursing actions to improvements in patients' lives in the longer term was a powerful motivator for staff. However, others have found that staff reward from experience of success might not be sufficient to maintain a new practice over the long term (Schnelle, McNees, Crooks, \& Ouslander, 1995). There was a strong drive from senior staff to focus on continence care, resulting in staff being consistently reminded, supported, and monitored. This is similar to research to improve continence care in nonacute settings, using monitoring and feedback of staff adherence to standards (Burgio, 1990; Engel et al., 1990).

\section{Limitations}

Findings are based on single interviews with mixed grades of nursing staff reflecting on recent experience, and could therefore be subject to recall or social influence bias. The genesis of the NPT framework was in the study of the integration of new technologies in health care rather than therapeutic procedures, although recent theorizing has extended earlier work (May, 2013).

A strength of the directed content analytic approach is the ability to support and develop existing theory, however using an existing theoretical framework can potentially introduce bias by making it more likely evidence will be found in support of, rather than refuting, the theory (Hsieh \& Shannon, 2005). Our data provided a good "fit" with the theory and all data could be coded within the pre-determined categories.

Provision of extra staff to facilitate implementation of the SVP could be viewed as a limitation. Although it is not possible to speculate regarding the extent to which stroke unit teams would have been able to introduce the SVP with their usual staffing levels, data from interviews completed post-intervention suggest staff in five out of eight sites were continuing without extra staffing, albeit in a modified form.

Our original intention was for staff to introduce the SVP without extra staff, based on the argument that staff were delivering continence care already and introduction of the SVP entailed planning and organizing continence care in a different way but not necessarily extra workload. Indeed, a consequence of SVP delivery could be reduced workload as patients re-gained continence or were "caught" before incontinence episodes. However, it was a condition of funding that extra staff were put in place. In practice, staffing levels varied widely across participating units: Units did not always receive the extra staff funded by the study (e.g., due to ICONS-funded staff going on sick or maternity leave) and lack of protection of ICONS-funded staff resulted in staff being moved to help on other wards.

\section{Conclusion and Implications for Future Trial Design}

The findings illustrate the crucial role of senior ward staff and the research nurse role in program oversight and coordination. Senior staff discussed the difficulty of "keeping a handle" on the program overall. Some attention could be given to supporting the work of monitoring the SVP in the paperwork, both at an individual patient level and ward level. Given the importance of visible improvement, making the reduction in workload more visible (e.g., less bed changes, reduced use of call bells) by regular ward audit and feedback might be useful. An increased therapeutic role for the HCA in managing continence care seems feasible, and the training given to staff in explaining the SVP needs to be checked to avoid potential misunderstanding by patients and relatives 
about the consequences of involvement in the SVP on length of stay.

The use of a process-based framework such as NPT was useful in highlighting potential mechanisms to maximize the success of new UI interventions. A future intervention could focus on ensuring SVP components stress the value of planning, coordination, and management of continence care; differentiate between regularized and individualized continence care; and ensure SVP components make continence process and outcome linkages more visible. Specific suggestions for improving the SVP's main decision points include the following:

- Assessing eligibility for the SVP: Revise inclusion guidelines for people with long-term continence problems, review use of the 3-day diary in acute settings, set up a screening reminder system;

- Supporting the pathway decision: Revise the continence assessment, and make the link between assessment results and the individualization of the management plan more explicit to avoid routine (as opposed to individualized) continence care;

- Supporting the timing decision: Review distraction and checking methods, revise, and improve methods for encouraging participation for patients who are anxious or irritated;

- Supporting adaptation of the SVP: Align the weekly review with similar activities, and visually track patients' trajectories to make improvement in outcome easily visible.

\section{Acknowledgment}

The authors thank all the staff for agreeing to be interviewed and for their work in introducing the SVP and taking part in the evaluation. They thank all participating patients and their families. Finally, the authors thank Pam Isherwood for helping with staff training, participating staff from the University of Central Lancashire Clinical Practice Research Unit (for stroke), Research Support Team, and the Lancashire Clinical Trials Unit.

\section{Authors' Note}

Implementation protocols for the systematic voiding program and interview schedules are available from the corresponding author. The views expressed in this publication are those of the authors and not necessarily those of the U.K. National Health Service, the U.K. National Institute for Health Research, or the U.K. Department of Health. In addition to the authors of this article, members of the ICONS Project Team include Bernadette Carter (College of Health and Wellbeing, University of Central Lancashire), Elaine McColl, Helen Rodgers (Medical School, Newcastle University), Katie Brittain (Institute of Health and Society \& Institute for Ageing and Health, Newcastle University), Andrew Walker (Robertson Centre for Biostatistics, Glasgow University), James Barrett (Arrowe Park Hospital,
Wirral), and Gemma Whiteley (Lancashire Teaching Hospitals NHS Foundation Trust). Members of the ICONS Patient, Public, and Carer Involvement Groups are Dave and Pat Brand, David Britt, May Griffiths, Philip Helvin, Brian James, Gill Pearl, Jane Whitewood, Jacqui Vella, Audrey and Richard Childs, Sean Crosby, Steve Hall, Anj Lewin, Liz Royle, Carole Scott, and Jean Wright.

\section{Declaration of Conflicting Interests}

The authors declared no potential conflicts of interest with respect to the research, authorship, and/or publication of this article.

\section{Funding}

The authors disclosed receipt of the following financial support for the research, authorship, and/or publication of this article: This paper presents independent research funded by the National Institute for Health Research (NIHR) under its Programme Grants for Applied Research Programme (Reference Number RP-PG-0707-10059). The views expressed are those of the author(s) and not necessarily those of the NHS, the NIHR or the Department of Health.

\section{References}

Bamford, J., Sandercock, P., Dennis, M., Warlow, C., Jones, L., McPherson, K., . . . Hughes, T. (1988). A prospective study of acute cerebrovascular disease in the community: The Oxfordshire Community Stroke Project 1981-86. 1. Methodology, demography and incident cases of firstever stroke. Journal of Neurology, Neurosurgery and Psychiatry, 51, 1373-1380.

Barer, D. H. (1989). Continence after stroke: Useful predictor or goal of therapy? Age and Ageing, 18, 183-191.

Bartley, A. (2012). The Hospital Pathways Project. Making it happen: Intentional rounding. London: The Kings Fund Point of Care and The Health Foundation.

Beck, C., Heacock, P., Mercer, S. O., Doan, R., O'Sullivan, P. S., Stevenson, J. G., . . . Hoskins, J. G. (2005). Sustaining a best-care practice in a nursing home. Journal for Healthcare Quality: Promoting Excellence in Healthcare, 27(4), 5-16.

Benzer, J. K., Beehler, S., Cramer, I. E., Mohr, D. C., Charns, M. P., \& Burgess, J. F., Jr. (2013). Between and within-site variation in qualitative implementation research. Implementation Science, 8, Article 4. doi:10.1186/1748-5908-8-4

Bonita, R. (1992). Epidemiology of stroke. The Lancet, 339, 342-344.

Booth, J. (2013). Continence care is every nurse's business. Nursing Times, 109(17-18), 12-16.

Booth, J., Kumlien, S., Zang, Y., Gustafsson, B., \& Tolson, D. (2009). Rehabilitation nurses practices in relation to urinary incontinence following stroke: A cross-cultural comparison. Journal of Clinical Nursing, 18, 1049-1058.

Brittain, K. R. (1998). Urinary symptoms and depression in stroke survivors. Age and Ageing, 27(Suppl. 1), 116-117.

Brittain, K. R., \& Castleden, C. M. (1998). Suicide in patients with stroke. Depression may be caused by symptoms 
affecting lower urinary tract. British Medical Journal, 317, 1016-1017.

Brittain, K. R., Perry, S. I., Peet, S. M., Shaw, C., Dallosso, H., Assassa, R. P., .. . Castleden, C. M. (2000). Prevalence and impact of urinary symptoms among community-dwelling stroke survivors. Stroke, 31, 886-891.

Brittain, K. R., \& Shaw, C. (2007). The social consequences of living with and dealing with incontinence-A carers perspective. Social Science \& Medicine, 65, 1274-1283.

Burgio, K. L. (1990). Behavioral training for stress and urge incontinence in the community. Gerontology, 36(Suppl. 2), 27-34.

Campbell, E. B., Knight, M., Benson, M., \& Colling, J. (1991). Effect of an incontinence training program on nursing home staff's knowledge, attitudes, and behavior. Gerontologist, $31,788-794$.

Canadian Stroke Network.(2010). Canadian bestpracticerecommendationsforstrokecareupdate 2010.Retrievedfrom http:// www.strokebestpractices.ca/wp-content/uploads/2011/04/ 2010BPR ENG.pdf

Cheater, F. C., Baker, R., Reddish, S., Spiers, N., Wailoo, A., Gillies, C., . . . Cawood, C. (2006). Cluster randomized controlled trial of the effectiveness of audit and feedback and educational outreach on improving nursing practice and patient outcomes. Medical Care, 44, 542-551.

Cooper, G., \& Watt, E. (2003). An exploration of acute care nurses' approach to assessment and management of people with urinary incontinence. Journal of Wound, Ostomy, and Continence Nursing, 30, 305-313.

Cowey, E., Smith, L. N., Booth, J., \& Weir, C. J. (2012). Urinary catheterization in acute stroke: Clinical realities. A mixed methods study. Clinical Rehabilitation, 26, 470-479.

Department of Health. (2012). Attributing the cost of health and social care Research \& Development (AcoRD). London: Author.

Dingwall, L., \& McLafferty, E. (2006). Do nurses promote urinary continence in hospitalized older people? An exploratory study. Journal of Clinical Nursing, 15, 1276-1286.

Dumoulin, C., Korner-Bitensky, N., \& Tannenbaum, C. (2007). Urinary incontinence after stroke: Identification, assessment, and intervention by rehabilitation professionals in Canada. Stroke, 38, 2745-2751.

Engel, B. T., Burgio, L. D., McCormick, K. A., Hawkins, A. M., Scheve, A. A., \& Leahy, E. (1990). Behavioral treatment of incontinence in the long-term care setting. Journal of the American Geriatrics Society, 38, 361-363.

Eustice, S., Roe, B., \& Paterson, J. (2000). Prompted voiding for the management of urinary incontinence in adults. Cochrane Database of Systematic Reviews, 1, CD002113.

Flottorp, S. A., Oxman, A. D., Krause, J., Musila, N. R., Wensing, M., Godycki-Cwirko, M., . . . Eccles, M. P. (2013). A checklist for identifying determinants of practice: A systematic review and synthesis of frameworks and taxonomies of factors that prevent or enable improvements in healthcare professional practice. Implementation Science, 8, Article 35. doi:10.1186/1748-5908-8-35.

Forsetlund, L., Bjorndal, A., Rashidian, A., Jamtvedt, G., O'Brien, M. A., Wolf, F., .. . Oxman, A. D. (2009).
Continuing education meetings and workshops: Effects on professional practice and health care outcomes. Cochrane Database of Systematic Reviews, 2, CD003030. doi:10.1002/14651858.CD003030.pub2

Harvey, G., Loftus-Hills, A., Rycroft-Malone, J., Titchen, A., Kitson, A., McCormack, B., \& Seers, K. (2002). Getting evidence into practice: The role and function of facilitation. Journal of Advanced Nursing, 37, 577-588.

Hsieh, H. F., \& Shannon, S. E. (2005). Three approaches to qualitative content analysis. Qualitative Health Research, $15,1277-1288$.

Intercollegiate Stroke Working Party. (2012). National clinical guideline for stroke (4th ed.). London: Royal College of Physicians.

Johnson, T. M., Ouslander, J. G., Uman, G. C., \& Schnelle, J. F. (2001). Urinary incontinence treatment preferences in Long-Term Care. Journal of the American Geriatrics Society, 49, 710-718.

Jordan, L. A., Mackey, E., Coughlan, K., Wyer, M., Allnutt, N., $\&$ Middleton, S. (2011). Continence management in acute stroke: A survey of current practices in Australia. Journal of Advanced Nursing, 67, 94-104.

Jorgensen, L., Engstad, T., \& Jacobsen, B. K. (2005). Selfreported urinary incontinence in noninstitutionalized longterm stroke survivors: A population-based study. Archives of Physical Medicine and Rehabilitation, 86, 416-420.

Keilman, L. J., \& Dunn, K. S. (2010). Knowledge, attitudes, and perceptions of advanced practice nurses regarding urinary incontinence in older adult women. Research and Theory for Nursing Practice, 24(4), 260-279.

Kolominsky-Rabas, P. L., Hilz, M. J., Neundoerfer, B., \& Heuschmann, P. U. (2003). Impact of urinary incontinence after stroke: Results from a prospective populationbased stroke register. Neurourology and Urodynamics, 22, 322-327.

Lawrence, E. S., Coshall, C., Dundas, R., Stewart, J., Rudd, A. G., Howard, R., \& Wolfe, C. D. A. (2001). Estimates of the prevalence of acute stroke impairments and disability in a multiethnic population. Stroke, 32, 1279-1284.

Levy-Storms, L., Schnelle, J. F., \& Simmons, S. F. (2007). What do family members notice following an intervention to improve mobility and incontinence care for nursing home residents? An analysis of open-ended comments. Gerontologist, 47, 14-20.

Marinkovic, S. P., \& Badlani, G. (2001). Voiding and sexual dysfunction after cerebrovascular accidents. Journal of Urology, 165, 359-370.

May, C. (2013). Towards a general theory of implementation. Implementation Science, 8, Article 18. doi:10.1186/17485908-8-18

May, C., Finch, T., Mair, F., Ballini, L., Dowrick, C., Eccles, M., ... Heaven, B. (2007). Understanding the implementation of complex interventions in health care: The normalization process model. BMC Health Services Research, 7, Article 148. doi:10.1186/1472-6963-7-148

May, C., Mair, F., Finch, T., MacFarlane, A., Dowrick, C., Treweek, S., . . . Montori, V. M. (2009). Development of a theory of implementation and integration: Normalization 
Process Theory. Implementation Science, 4, Article 1. doi:10.1186/1748-5908-4-29

McClurg, D., Booth, J., Eustice, S., Burke, J., Jamieson, K., \& Hagen, S. (2013). A multi-professional UK wide survey of undergraduate continence education. Neurourology and Urodynamics, 32(3), 224-229.

McEvoy, R., Ballini, L., Maltoni, S., O’Donnell, C. A., Mair, F. S., \& MacFarlane, A. (2014). A qualitative systematic review of studies using the normalization process theory to research implementation processes. Implementation Science, 9, Article 2

Medical Research Council. (2008). Developing and evaluating complex interventions: New guidance. London: Author.

Miller, E. L., Murray, L., Richards, L., Zorowitz, R. D., Bakas, T., Clark, P., \& Billinger, S. A. (2010). Comprehensive overview of nursing and interdisciplinary rehabilitation care of the stroke patient: A scientific statement from the American Heart Association. Stroke, 41, 2402-2448.

Nakayama, H., Jorgensen, H. S., Pedersen, P. M., Raaschou, H. O., \& Olsen, T. S. (1997). Prevalence and risk factors of incontinence after stroke. The Copenhagen Stroke Study. Stroke, 28(1), 58-62.

National Collaborating Centre for Women's and Children's Health. (2013). Urinary incontinence in women: The management of urinary incontinence in women (NICE Clinical Guideline CG171). London: National Institute for Health and Care Excellence.

National Stroke Foundation. (2010). Clinical guidelines for stroke management 2010. Melbourne: Author.

Ouslander, J. G., Griffiths, P., McConnell, E., Riolo, L., \& Schnelle, J. (2005). Functional incidental training: Applicability and feasibility in the Veterans Affairs nursing home patient population. Journal of the American Medical Directors Association, 6(2), 121-127.

Patel, M., Coshall, C., Rudd, A. G., \& Wolfe, C. D. (2001). Natural history and effects on 2-year outcomes of urinary incontinence after stroke. Stroke, 32(1), 122-127.

Pilcher, M., \& MacArthur, J. (2012). Patient experiences of bladder problems following stroke. Nursing Standard, 26(36), 39-46.

Roe, B., Flanagan, L., Jack, B., Shaw, C., Williams, K., Chung, A., \& Barrett, J. (2011). Systematic review of descriptive studies that investigated associated factors with the management of incontinence in older people in care homes. International Journal of Older People Nursing, 8(1), 29-49.

Royal College of Physicians. (2014). Sentinel Stroke National Audit Programme (SSNAP) Clinical audit April-June 2014 Public Report. London: Author.

Sampselle, C. M., Wyman, J. F., Thomas, K. K., Newman, D. K., Gray, M., Dougherty, M., \& Burns, P. A. (2000). Continence for women: Evaluation of AWHONN's third research utilization project. Association of Women's Health Obstetric and Neonatal Nurses. Journal of Obstetric, Gynecologic, \& Neonatal Nursing, 29(1), 9-17.

Schnelle, J. F., McNees, P., Crooks, V., \& Ouslander, J. G. (1995). The use of a computer-based model to implement an incontinence management program. Gerontologist, 35, 656-665.

Stetler, C. B., Legro, M. W., Rycroft-Malone, J., Bowman, C., Curran, G., Guihan, M., ... W Wallace, C. M. (2006). Role of "external facilitation" in implementation of research findings: A qualitative evaluation of facilitation experiences in the Veterans Health Administration. Implementation Science, 1 , Article 23.

Thomas, L. H., French, B., Burton, C. R., Sutton, C., Forshaw, D., Dickinson, H., . . . on behalf of the ICONS project team and the ICONS Patient, Public and Carer Involvement Groups. (2014). Evaluating a systematic voiding programme for patients with urinary incontinence after stroke in secondary care using soft systems analysis and Normalisation Process Theory: Findings from the ICONS case study phase. International Journal of Nursing Studies, $51,1308-1320$.

Thomas, L. H., French, B., Sutton, C. J., Forshaw, D., Leathley, M. J., Burton, C. R., . . . on behalf of the ICONS: Identifying Continence OptioNs after Stroke project team and the ICONS Patient, Public and Carer Involvement Groups. (2015). ICONS: Identifying Continence OptioNs after Stroke: An evidence synthesis, case study and exploratory cluster randomised controlled trial of the introduction of a systematic voiding programme for patients with urinary incontinence after stroke in secondary care. Programme Grants for Applied Research, 3(1), 1-602.

Thomas, L. H., Watkins, C. L., French, B., Sutton, C., Forshaw, D., \& Cheater, F., . . . The ICONS Project Team and the ICONS Patient, Public and Carer Involvement Groups. (2011). Study protocol: ICONS: Identifying continence options after stroke: A randomised trial. Trials, 12, Article 131

Wagg, A., Lowe, D., Peel, P., \& Potter, J. (2008). Continence care for older people in England and Wales: Data from a national audit. Journal of Wound, Ostomy, \& Continence Nursing, 35(2), 215-220.

Wallace, S. A., Roe, B., Williams, K., \& Palmer, M. (2004). Bladder training for urinary incontinence in adults. Cochrane Database of Systematic Reviews, 1, CD001308.

Wikander, B., Ekelund, P., \& Milsom, I. (1998). An evaluation of multidisciplinary intervention governed by functional independence measure (FIMSM) in incontinent stroke patients. Scandinavian Journal of Rehabilitation Medicine, 30(1), 15-21.

Williams, K. S., Crichton, N. J., \& Roe, B. (1997). Disseminating research evidence. A controlled trial in continence care. Journal of Advanced Nursing, 25, 691-698.

Williams, M. P., Srikanth, V., Bird, M., \& Thrift, A. G. (2012). Urinary symptoms and natural history of urinary continence after first-ever stroke-A longitudinal populationbased study. Age and Ageing, 41, 371-376.

\section{Author Biographies}

Beverley French, $\mathrm{PhD}$, was a reader in evidence-based health care at the University of Central Lancashire, United Kingdom (now retired). 
Lois H. Thomas, $\mathrm{PhD}$, is a reader in health services research at the University of Central Lancashire, United Kingdom.

Joanna Harrison, MA, is a research capacity delivery manager, National Institute for Health Research (NIHR) Collaboration for Leadership in Applied Health Research and Care North West Coast based at the University of Central Lancashire, United Kingdom.

Christopher R. Burton, $\mathrm{PhD}$, is Noreen Edwards Chair of rehabilitation and nursing research at Bangor University, United Kingdom, and improvement science fellow with the Health Foundation, United Kingdom.

Denise Forshaw, PGCert, is the senior clinical trials manager, Lancashire Clinical Trials Unit based at the University of Central Lancashire, United Kingdom.
Joanne Booth, $\mathrm{PhD}$, is a reader in applied health research at Glasgow Caledonian University, United Kingdom.

David Britt, $\mathrm{PhD}$, is a champion of public and patient involvement in research and an honorary research fellow in primary care at the University of Liverpool, United Kingdom.

Francine M. Cheater, $\mathrm{PhD}$, is professor of public health and implementation science at the University of East Anglia, United Kingdom.

Brenda Roe, $\mathrm{PhD}$, is a professor of health research at Edge Hill University, United Kingdom.

Caroline L. Watkins, $\mathrm{PhD}$, is a professor of stroke and older people's care at the University of Central Lancashire, United Kingdom and a professorial fellow in stroke care at the Australian Catholic University, Australia. 